\title{
Multiple drilling is not effective in reducing the rate of conversion to Total hip Arthroplasty in early-stage nontraumatic osteonecrosis of the femoral head: a case- control comparative study with a natural course
}

\author{
Zunhan Liư ${ }^{\dagger}$ Xuetao Yang ${ }^{\dagger}$, Yuhan Li, Wei-Nan Zeng, Enze Zhao and Zongke Zhou ${ }^{*}$
}

\begin{abstract}
Background: To determine whether multiple drilling is effective in postponing the need for total hip arthroplasty (THA) in early-stage nontraumatic osteonecrosis of the femoral head (ONFH).

Methods: We identified 514 patients who were diagnosed with early-stage ONFH between January 2008 and December 2018. One hundred ninety-six patients underwent multiple drilling, and 318 patients had a natural course of progression. One hundred fifty-nine patients were selected for each group after case-control matching for preoperative demographics and modified Ficat and Arlet stage. The rates of THA conversion were compared. We also performed Cox regression to identify risk factors associated with THA conversion in patients who underwent multiple drilling.

Results: Kaplan-Meier survivorship with an endpoint of THA for nontraumatic reasons were not significantly different between the multiple drilling group (75.6, 95\% confidence interval 67.8-83.4\%) and the natural course group (72.2, 95\% confidence interval 64.8-79.6\%) at 5 years (log-rank, $P=.191)$. In the Cox regression model, a larger extent of necrotic lesion, bone marrow edema (BME), and higher postoperative work intensity significantly increased the risk of THA conversion $(P<.05)$. Among patients treated with autogenous bone grafting, there was a lower risk of failure in patients with necrotic lesion less than $15 \%(P<.05)$.
\end{abstract}

Conclusions: Multiple drilling is not effective in reducing the rate of THA conversion in early-stage nontraumatic ONFH. The risk of conversion to THA after multiple drilling is increased by a larger extent of necrotic lesion, presence of BME, and higher postoperative work intensity in patients with early-stage ONFH.

\footnotetext{
* Correspondence: zhouzongke@scu.edu.cn

${ }^{\dagger}$ Zunhan Liu and Xuetao Yang contributed equally to this work.

Department of Orthopedic Surgery, West China Hospital, West China Medical

School, Sichuan University, \#37 Guoxue Road, Chengdu, Sichuan Province

610041, People's Republic of China
}

C C The Author(s). 2021 Open Access This article is licensed under a Creative Commons Attribution 4.0 International License, which permits use, sharing, adaptation, distribution and reproduction in any medium or format, as long as you give appropriate credit to the original author(s) and the source, provide a link to the Creative Commons licence, and indicate if changes were made. The images or other third party material in this article are included in the article's Creative Commons licence, unless indicated otherwise in a credit line to the material. If material is not included in the article's Creative Commons licence and your intended use is not permitted by statutory regulation or exceeds the permitted use, you will need to obtain permission directly from the copyright holder. To view a copy of this licence, visit http://creativecommons.org/licenses/by/4.0/. The Creative Commons Public Domain Dedication waiver (http://creativecommons.org/publicdomain/zero/1.0/) applies to the data made available in this article, unless otherwise stated in a credit line to the data. 
Trial registration: The trial was registered in the Chinese Clinical Trial Registry (ChiCTR2000035180) dated 2 August 2020.

Keywords: Multiple drilling, Risk factors, Total hip arthroplasty, Autogenous bone grafting, Osteoarthritis

\section{Background}

Nontraumatic osteonecrosis of the femoral head $(\mathrm{ONFH})$ is a clinical entity originating from impaired circulation of femoral head terminal blood flow, if not treated effectively, leading to femoral head collapse and, ultimately, arthritis of the hips. Total hip arthroplasty (THA) is one of the most successful health care interventions for patients with postcollapse ONFH [1]. However, since the disease often affects young patients, prosthetic arthroplasties rarely last for their lifetimes and usually necessitate multiple corrective procedures [2]. Therefore, joint-preserving treatment should be considered at the early stage to relieve pain and prevent progression.

Core decompression of the femoral head is a wellestablished joint-preserving procedure proposed to treat early-stage ONFH. However, a single large core tract has the risk of weakening subchondral bone support, which leads to a further collapse of the femoral head [3]. To overcome the limitations of this surgery, the multiple small-diameter drilling technique has been introduced and can provide the same benefit as core decompression [4]. In theory, this technique is a minimally invasive intervention that partly removes necrotic bone, provides mechanical support, and does not change the anatomic structure of the femoral head [3, 5-10]. Prior studies have demonstrated improvements in clinical symptoms after multiple drilling, failure of multiple drilling procedures is a main concern in patients and surgeons. However, due to homogenous study populations, determination of failure, sample sizes and follow-up duration, the efficacy of multiple drilling procedures in reducing the rate of conversion to THA remains controversial. Although there appears to be a consensus that core decompression or multiple drilling is more effective than nonoperative management for early-stage $\mathrm{ONFH}$, the meta-analysis and review are on the basis of a few older small-scale randomized studies with shortterm follow-up, which only provide limited quality of evidence $[11,12]$. To our knowledge, there is few studies evaluating the efficacy of multiple drilling regimens in conversion to THA by comparing early-stage ONFH patients undergoing multiple drilling with the natural course.

Therefore, the primary purpose of the study was to compare the rate of conversion to THA in early-stage ONFH patients undergoing multiple drilling to that among patients undergoing a natural course.
Furthermore, we identified risk factors for failure in a relatively large cohort of patients undergoing multiple drilling. The need for THA was the primary end point for defining failure. Additionally, we analyzed whether autogenous bone grafting is a protective factor against the need for THA. We hypothesized that there was significant difference in the rates of THA conversion in early-stage ONFH patients in the multiple drilling and the natural course group.

\section{Methods \\ Patients}

After approval from the institutional Clinical Trials and Biomedical Ethics Committee was obtained and the trial was registered at ClinicalTrials.gov, patients with earlystage nontraumatic ONFH were identified for eligibility, and all patients provided their written informed consent. We performed a retrospective, single-center, cohort study that enrolled early-stage nontraumatic ONFH from January 2008 to December 2018. The early-stage ONFH was defined as patients with modified Ficat and Arlet I and IIA/B stage [13]. The inclusion criteria included the following: (1) patients aged $>18$ and $<65$ years with nontraumatic ONFH, (2) patients who simultaneously underwent multiple drilling at the hip with early-stage osteonecrosis and THA at the contralateral side, (3) hips classification per the Ficat staging criteria as I and IIA/B stage according to modified Ficat and Alert classification for ONFH determined by preoperative X-ray and magnetic resonance (MR) imaging, and (4) only autogenous bone grafting, for patients who underwent bone grafting. Patients were excluded if they had or received any of the following: (1) pharmacological agents, including bisphosphonates, iloprost, enoxaparin, and statins; (2) biophysical therapies, including corporeal shockwave therapy and pulsed electromagnetic field therapy; (3) ankylosing spondylitis, osteoarthritis, and sickle cell disease; (4) femoral neck fracture (FNF) or femoral intertrochanteric fracture (FIF) during the period of follow-up; or (5) death, incomplete clinical or radiological data, and loss to follow-up. The indication for multiple drilling were restricted primarily to modified Ficat and Arlet stage I and IIA/B. All demographic data, including age, sex, mean body mass index (BMI), clinical and radiographic evaluations, intraoperative findings, and interventions, were collected. The search included all patients operated on by any of the 4 senior 
surgeons specializing in total joint arthroplasty in our unit.

We identified 196 patients diagnosed with early-stage ONFH who underwent multiple drilling between January 2008 and December 2018 and were followed for a minimum of 2 years. Of these, one patient was excluded due to death, eight patients were excluded due to loss to follow-up, six patients were excluded due to incomplete clinical or radiological data, eight patients were excluded due to FNF or FIF, and two patients were excluded due to receiving bisphosphonates. We also identified 318 patients who underwent THA and were diagnosed with early-stage ONFH at the contralateral hip that had a natural course of progression during the same follow-up period and included them, as the control group. Patients with a natural course of progression was defined as patients did not receive a therapeutic intervention for the purpose of treating or preventing osteonecrosis of the affected femoral head, including operative treatment, physical therapy, and biophysical stimulation. Patients with a natural course and patients who underwent multiple drilling were matched for sex, age at surgery (up to \pm 10 years), date of surgery (up to \pm 12 months), etiology, modified Ficat and arlet stage, and extent of necrotic lesion at a 1:1 ratio. The diagnosis and classification of ONFH was first defined by the ICD code and then confirmed by an orthopedic specialist based on their radiographic images. The final cohort consisted of 159 consecutive patients with a complete clinical and radiological follow-up for analysis, including 138 men (86.8\%) and 21 women. Of note, as the indication for conversion to THA in so variable among surgeons, indication for conversion to THA in the current study was restricted to a new collapse of greater than $2 \mathrm{~mm}$ on plain radiographs for nontraumatic reason or onset of hip pain with a Harris hip score (HHS) less than 75 [14]. Radiographic progression was defined as a new collapse of greater than $2 \mathrm{~mm}$ (Ficat III stage) with or without decreased joint space. At the time of the latest follow-up, a total of 34 hips $(21.4 \%)$ had been converted to THA because of onset of symptoms and collapse of the femoral head. These hips were compared with the subgroup to 125 hips (78.6\%) following multiple drilling that had not been converted to THA, as shown in Fig. 1.

The surgical procedure of multiple drilling was performed as described by Mont et al. [15]. Multiple drilling was performed with patients under general anesthesia and in the supine position. The affected hip was rotated internally at $15^{\circ}$. A straight incision was created from $1.5 \mathrm{~cm}$ under the tip of the greater trochanter. A 3.0- to $5.5-\mathrm{mm}$ guide pin was inserted into the lateral cortex of the femur toward the necrotic lesions from proximal to distal. After insertion into $10-$ to $12-\mathrm{mm}$ pieces, the alignment of the guide pin was checked under fluoroscopy guidance to ensure that the pin was in the correct direction. The pin was advanced through the femoral neck into the femoral head at the appropriate depth. Similarly, another one or two additional parallel pins were inserted toward the necrotic lesions. Next, drill channels were created using a cannulated drill bit until it reached $5 \mathrm{~mm}$ beneath the subchondral bone. For 66 multiple drilling patients who received autogenous bone grafting, cancellous bone harvested from the contralateral femoral head was split into multiple pieces and packed into small holes with hammer blowing.

\section{Assessments}

The etiologies, with or without preoperative symptoms, the preoperative HHS, and the postoperative work intensity [16] were recorded. Radiographic images were

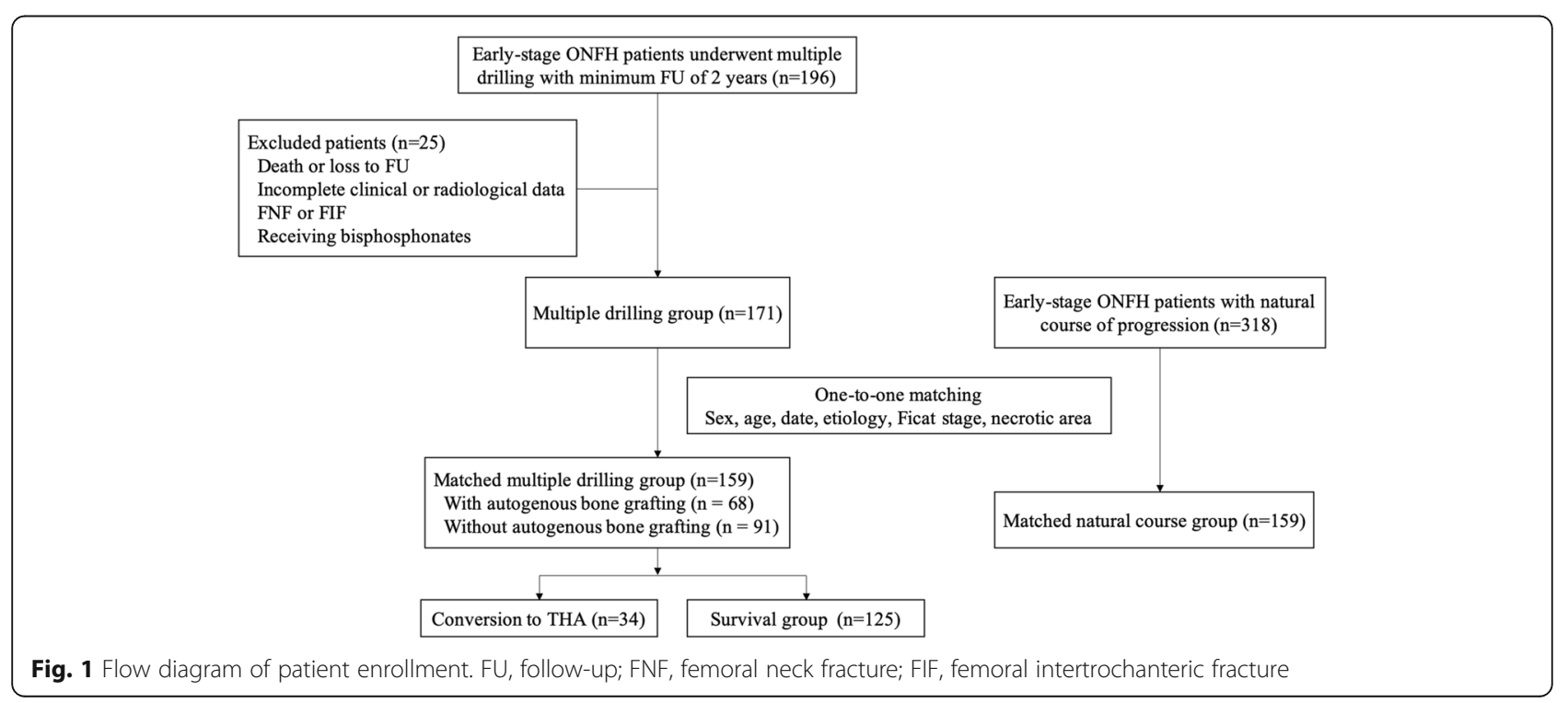


evaluated by two independent observers, who were blinded to whether the patient underwent multiple drilling, autogenous bone grafting, and conversion to THA. These included X-ray parameters (postoperative alpha angles, superior and medial joint space, radiographic parameters of hip dysplasia, and radiographic parameters of CAM-type femoroacetabular impingement (FAI)) and MR imaging parameters (location of necrotic lesion, extent of necrotic lesion, and bone marrow edema (BME)). Lesion location was assessed on midcoronal MR imaging using a system described by Sugano et al. [17]. The extent of the necrotic lesion was measured according to the method described by Steinberg et al. (mild, $<15 \%$; moderate, $15-30 \%$; severe, $>30 \%$ ) [18], as shown in Fig. 2. The process of measurement involved outlining the necrotic lesion and the entire femoral head on both the anteroposterior and lateral MRI, determining the percentage of necrotic lesion in each of views separately. This method has been proved to be more accurate and reasonably reliable compared with other angular measurements [19].

\section{Statistical analysis}

First, the distribution of data was tested by KolmogorovSmirnov's test. Continuous variables were analyzed with the independent-sample t-test for normally distributed data or the Mann-Whitney U test for skewness distribution data, while categorical variables were compared using Fisher's exact test. The primary analyses were to evaluate the influence of multiple drilling by comparing the rates of conversion to THA in patients following multiple drilling and patients with a natural course of progression by KaplanMeier curves and log-rank tests. Next, we created univariate and multivariate Cox proportional hazards to identify independent risk factors that affect survival rates in the multiple drilling group while adjusting for other covariates. Covariates with a $P$ value $<.05$ by univariate analysis were integrated into the multivariate regression model. Finally, we analyzed the potential influence of autogenous bone grafting on the failure rate using Kaplan-Meier and logrank tests. All analyses were carried out using SPSS Version 26 (IBM Corporation, Armonk, NY, USA). For this study, the level of statistical significance was set at $P<.05$.

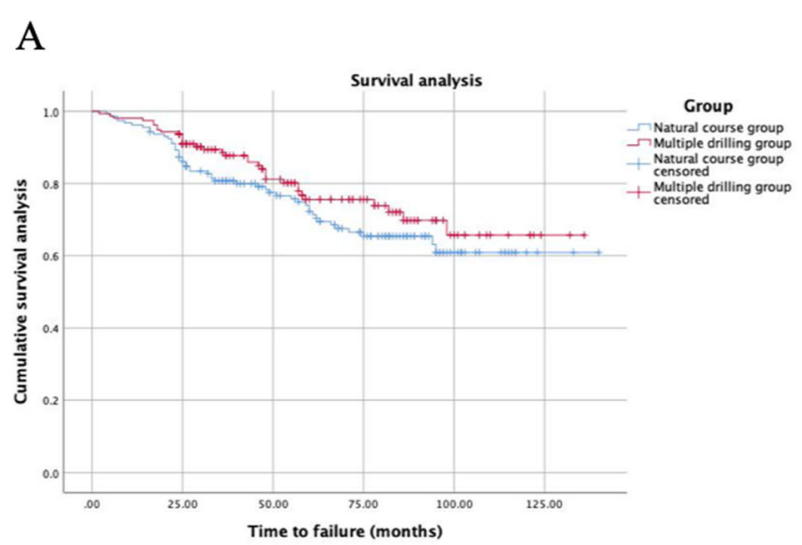

B

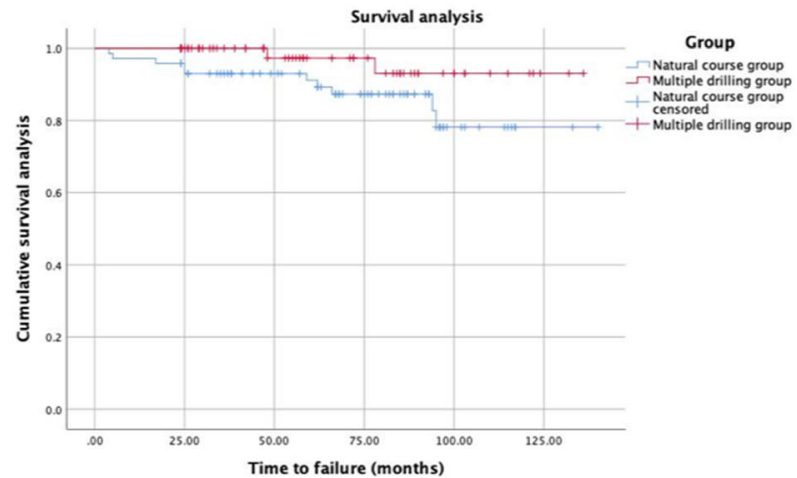

$\mathrm{C}$

D
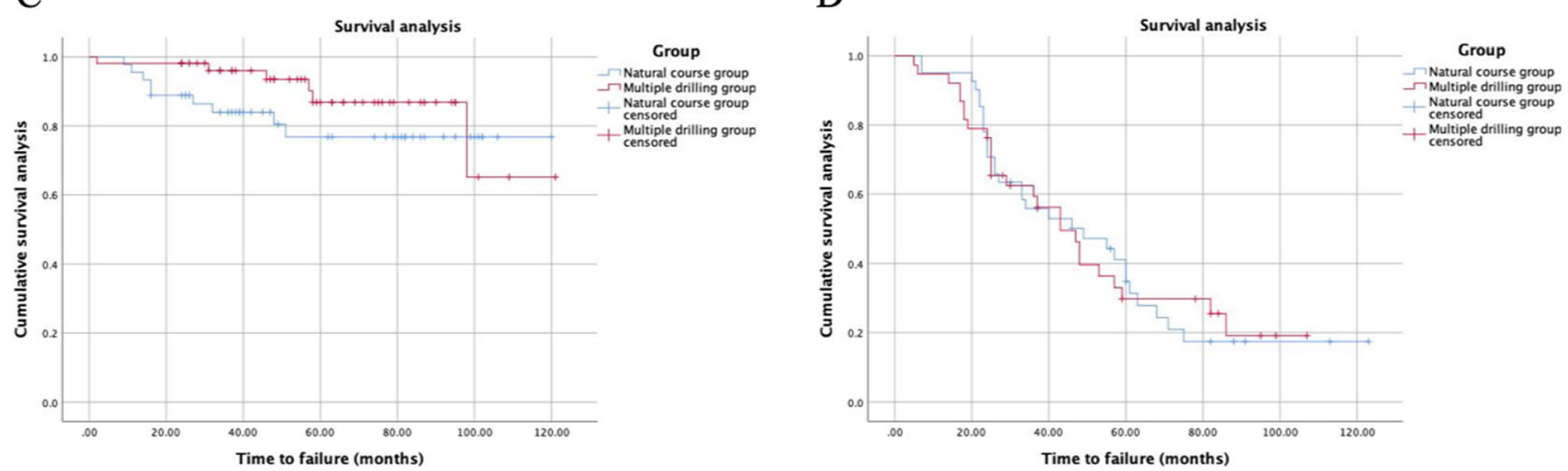

Fig. 2 Radiographs of a patient in the multiple drilling group (5 I years old, male, and corticosteroid induced). A X-ray, B T2 image on transverse position, C T1 image on transverse position, and (D) T2 image on midcoronal position before surgery showed that the right femoral head had collapsed with osteoarthritis and that the left femoral head had cystic degeneration. The percentage extent of necrotic lesion was categorized to 15-30\%. E Patients underwent simultaneous THA and multiple drilling. Forty-nine months after multiple drilling procedures, the left femoral head collapsed $(\mathbf{F})$, and patients received THA in the left hip $(\mathbf{G})$. Postoperative radiographic view $(\mathbf{H})$ at the 4-year follow-up after left THA demonstrated that the acetabular and femoral components were stable 


\section{Results}

Comparison between patients with a natural course and who underwent multiple drilling

We matched the multiple drilling patients to 159 patients with a natural course of progression. Table 1 shows and compares demographic characteristics and radiological measurements between the 2 groups. The mean follow-up time (standard deviation) was 58.5 months (31.0) for all patients, 56.2 (30.2) months for the multiple drilling group and 60.8 (31.7) months for the natural course group $(P=.191)$. In the multiple drilling group, the survival rates were $98.1 \%$ (95\% confidence interval 95.9-99.9\%) at 1 year, 75.6\% (95\% confidence interval $67.8-83.4 \%)$ at 5 years and $65.7 \%(95 \%$

Table 1 Baseline characteristics of patients

\begin{tabular}{|c|c|c|c|c|c|c|}
\hline Variable & $\begin{array}{l}\text { Failure group } \\
(n=34)\end{array}$ & $\begin{array}{l}\text { Survival group } \\
(n=125)\end{array}$ & $P$ value & $\begin{array}{l}\text { Multiple drilling group } \\
(n=159)\end{array}$ & $\begin{array}{l}\text { Control group } \\
(n=159)\end{array}$ & $P$ value \\
\hline Age at surgery (y) & $42.7 \pm 7.8$ & $43.2 \pm 8.5$ & $.767^{\mathrm{a}}$ & $43.1 \pm 8.4$ & $44.5 \pm 8.5$ & $.131^{\mathrm{a}}$ \\
\hline Gender (male/female) & $30 / 4$ & $108 / 17$ & $1.000^{b}$ & $138 / 21$ & $138 / 21$ & $1.000^{b}$ \\
\hline Body mass index $\left(\mathrm{kg} / \mathrm{m}^{2}\right)$ & $24.9 \pm 4.8$ & $23.9 \pm 3.6$ & $.178^{\mathrm{a}}$ & $24.2 \pm 3.9$ & $23.8 \pm 2.9$ & $.307^{\mathrm{a}}$ \\
\hline Etiology & & & $.201^{b}$ & & & $1.000^{b}$ \\
\hline Alcohol abuse & $24(70.6 \%)$ & $80(64.0 \%)$ & & $104(65.4 \%)$ & $104(65.4 \%)$ & \\
\hline Corticosteroid use & $7(20.6 \%)$ & $18(14.4 \%)$ & & $25(15.7 \%)$ & $25(15.7 \%)$ & \\
\hline Idiopathic & $3(8.8 \%)$ & $27(21.6 \%)$ & & $30(18.9 \%)$ & $30(18.9 \%)$ & \\
\hline Modified Ficat and Arlet stage & & & $<.001^{\mathrm{b}}$ & & & $1.000^{b}$ \\
\hline Stage I & $2(5.9 \%)$ & $14(11.2 \%)$ & & $16(10.1 \%)$ & $16(10.1 \%)$ & \\
\hline Stage \| A & $10(29.4 \%)$ & $92(73.6 \%)$ & & $102(64.2 \%)$ & $102(64.2 \%)$ & \\
\hline Stage \| B & $22(64.7 \%)$ & $19(15.2 \%)$ & & $41(25.8 \%)$ & $41(25.8 \%)$ & \\
\hline Asymptomatic/sypmptomatic & $23 / 11$ & $77 / 48$ & $.555^{\mathrm{b}}$ & $100 / 59$ & $93 / 66$ & $.491^{b}$ \\
\hline Preoperative Harris score & $88.2 \pm 4.9$ & $87.4 \pm 5.1$ & $.395^{\mathrm{a}}$ & $87.6 \pm 5.1$ & $87.5 \pm 8.1$ & $.947^{\mathrm{a}}$ \\
\hline Necrotic location & & & $<.001^{\mathrm{b}}$ & & & $.235^{\mathrm{b}}$ \\
\hline A & $2(5.9 \%)$ & $20(16.0 \%)$ & & $22(13.8 \%)$ & $32(20.1 \%)$ & \\
\hline $\mathrm{B}$ & $1(2.9 \%)$ & $45(36.0 \%)$ & & $46(28.9 \%)$ & $34(21.4 \%)$ & \\
\hline $\mathrm{C} 1$ & $12(35.3 \%)$ & $47(37.6 \%)$ & & $59(37.1 \%)$ & $55(34.6 \%)$ & \\
\hline $\mathrm{C} 2$ & $19(55.9 \%)$ & $13(10.4 \%)$ & & $32(20.1 \%)$ & $38(23.9 \%)$ & \\
\hline Extent of necrotic lesion & & & $<.001^{\mathrm{b}}$ & & & $1.000^{b}$ \\
\hline$<15 \%$ & $2(5.9 \%)$ & $64(51.2 \%)$ & & $66(41.5 \%)$ & $66(41.5 \%)$ & \\
\hline $15-30 \%$ & $6(17.6 \%)$ & $49(39.2 \%)$ & & $55(34.6 \%)$ & $55(34.6 \%)$ & \\
\hline$>30 \%$ & $26(76.5 \%)$ & $12(9.6 \%)$ & & $38(23.9 \%)$ & $38(23.9 \%)$ & \\
\hline Bone marrow edema (no. of hips) & $15(44.1 \%)$ & $13(10.4 \%)$ & $<.001^{b}$ & $27(17.0 \%)$ & $20(12.6 \%)$ & $.343^{b}$ \\
\hline Alpha angle & $47.8 \pm 7.1$ & $48.2 \pm 7.2$ & $.825^{\mathrm{a}}$ & $48.1 \pm 7.1$ & $50.1 \pm 6.9$ & $.009^{a}$ \\
\hline CAM type FAI (no. of hips) & $3(8.8 \%)$ & $14(11.2 \%)$ & $1.000^{b}$ & $17(10.7 \%)$ & $25(15.7 \%)$ & $.246^{b}$ \\
\hline Hip dysplasia (no. of hips) & $3(8.8 \%)$ & $13(10.4 \%)$ & $1.000^{\mathrm{b}}$ & $16(10.1 \%)$ & $12(7.5 \%)$ & $.553^{b}$ \\
\hline Medial joint space (mm) & $9.1 \pm 2.2$ & $9.4 \pm 2.0$ & $.355^{\mathrm{a}}$ & $9.3 \pm 2.2$ & $9.5 \pm 2.2$ & $.400^{a}$ \\
\hline Superior joint space (mm) & $4.6 \pm 0.9$ & $4.6 \pm 1.1$ & $.853^{\mathrm{a}}$ & $4.6 \pm 1.0$ & $4.5 \pm 1.0$ & $.668^{a}$ \\
\hline Postoperative Work intensity & & & $<.001^{\mathrm{b}}$ & & & $.164^{b}$ \\
\hline Grade 0-1 & $14(41.2 \%)$ & $109(87.2 \%)$ & & $123(77.4 \%)$ & $111(69.8 \%)$ & \\
\hline Grade 2 & $12(35.3 \%)$ & $10(8.0 \%)$ & & $22(13.8 \%)$ & $35(22.0 \%)$ & \\
\hline Grade 3-4 & $8(23.5 \%)$ & $6(4.8 \%)$ & & $14(8.8 \%)$ & $13(8.2 \%)$ & \\
\hline Bone grafting (no. of hips) & $17(50.0 \%)$ & $51(32.1 \%)$ & $.435^{\mathrm{b}}$ & & & \\
\hline Failure (no. of hips) & & & & $34(21.4 \%)$ & $49(30.8 \%)$ & $.191^{c}$ \\
\hline
\end{tabular}

FAl femoroacetabular impingement

a Student $t$ test

${ }^{b}$ Fisher's exact test

c Log-rank text 
confidence interval $53.7-77.7 \%)$ at 10 years, and they were 96.2\% (95\% confidence interval 93.3-99.1\%), 72.2\% (95\% confidence interval 64.8-79.6\%), and 60.9\% (95\% confidence interval 51.1-70.7\%), respectively, in the natural course group (log-rank, $P=.191$ ). A total of 32 patients $(20.1 \%)$ in multiple drilling group and 27 patients $(17.0 \%)$ in natural course group had radiographic progression, and a total of 34 patients (21.4\%) in multiple drilling group and 30 patients (18.9\%) in natural course group went on to THA within the follow-up. Among patients with extent of necrotic lesion less than $15 \%$, patients receiving multiple drilling $(n=66)$ had near significant influence on survival rate compared to patients $(n=73)$ with natural course $(P=.069)$. However, neither extent of necrotic lesion of $15-30 \%$ nor necrotic lesion $>30 \%$ with multiple drilling had an influence on conversion to THA compared to patients with natural course ( $P=.227, .995$, respectively), as shown in Fig. 3.

\section{Risk factors for failure after multiple drilling}

After adjustment for covariates using the Cox proportional hazard model, the extent of necrotic lesion, the presence of BME on MR imaging, and postoperative work intensity were associated with a higher rate of conversion to THA after multiple drilling procedures $(P=.001, P=.046$, and $P=.001)$. The results of the binary regression analysis are summarized in Table 2.

\section{Influence of autogenous bone grafting in multiple drilling patients}

In the Kaplan-Meier analyses, autogenous bone grafting $(n=68)$ in multiple drilling patients had no influence on the survival rate compared to patients $(n=91)$ with multiple drilling alone $(P=.373)$. However, multiple drilling patients with extent of necrotic lesion less than $15 \%$ who received autogenous bone grafting $(n=28)$ had a significantly lower risk of conversion to THA than patients $(n=38)$ receiving multiple drilling alone $(P=.007)$. Among patients with necrotic lesion of $15-30 \%$, patients who received autogenous bone grafting $(n=23)$ had no influence on survival rate compared to patients $(n=32)$ receiving multiple drilling alone $(P=.453)$. Among patients with the extent of necrotic lesion $>30 \%$, patients who received autogenous bone grafting $(n=17)$ also had no influence on survival rate compared to patients $(n=$ 21) receiving multiple drilling alone $(P=.657)$, as shown in Fig. 4.
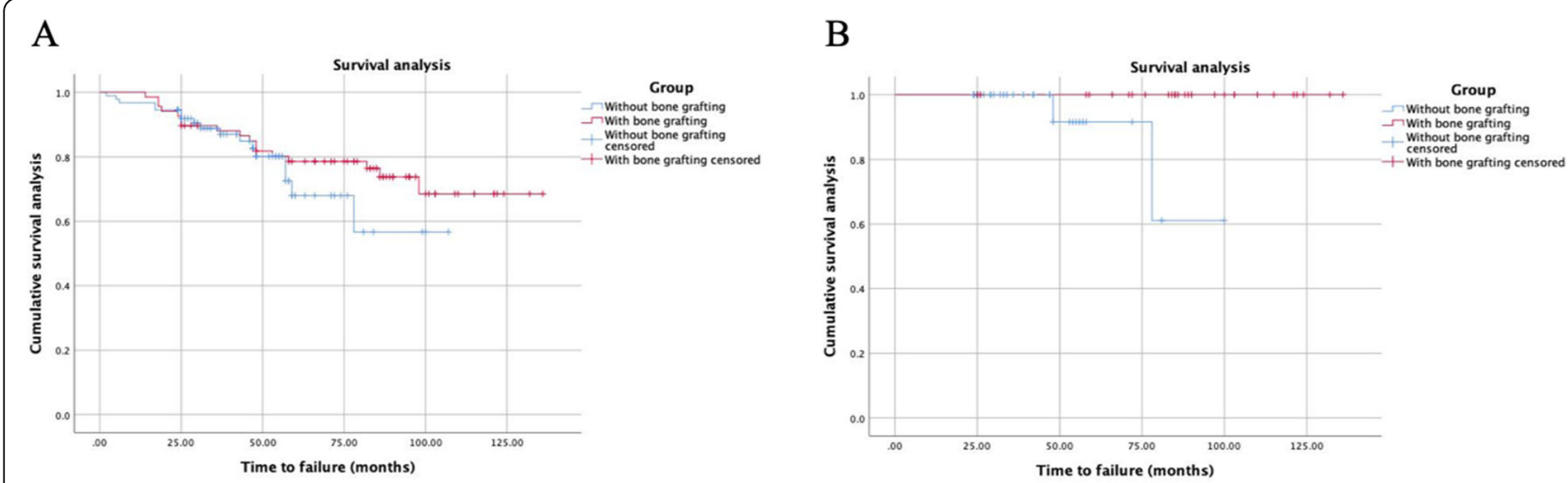

$\mathrm{C}$

D
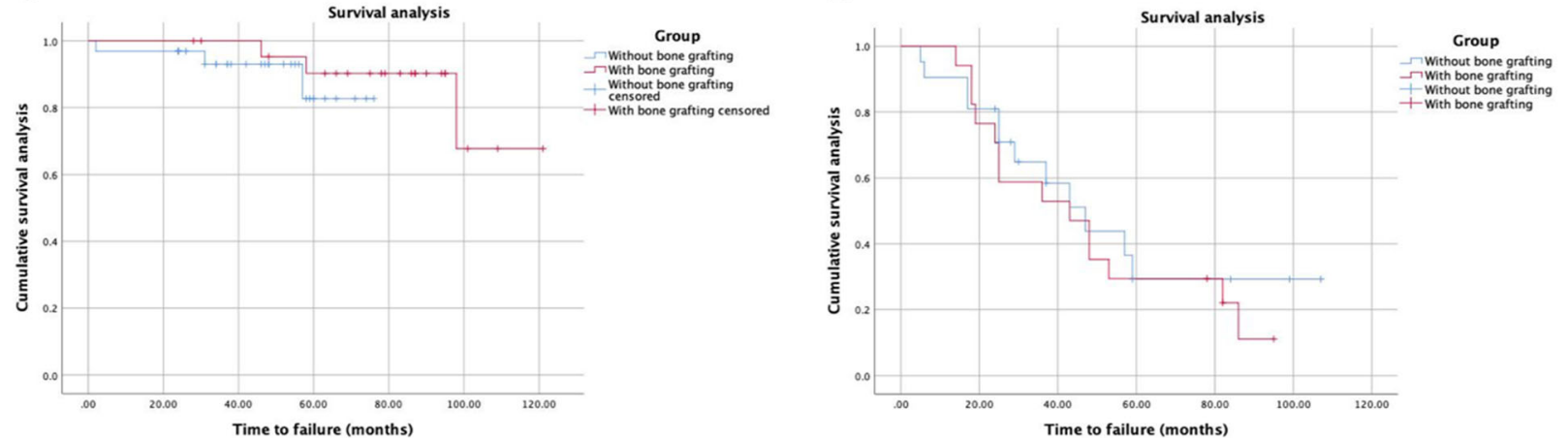

Fig. 3 A Survival analysis of conversion to THA between patients who underwent multiple drilling and patients with a natural course of osteonecrosis progression. The difference was not statistically significant. (Kaplan-Meier method with long-rank test $P=.191$ ). Depending on the different extent of necrotic lesion, patients receiving multiple drilling showed near significant difference on survival rate in patients with necrotic lesion $<15 \%$ (B). However, neither extent of necrotic lesion of 15-30\% (C) nor necrotic areas $>30 \%$ (D) with multiple drilling had an influence on conversion to THA compared to patients with natural course $(P=.227, .995$, respectively) 
Table 2 Univariate and multivariate Cox regression analysis of association between different factors and failure of core decompression

\begin{tabular}{|c|c|c|c|c|c|c|}
\hline \multirow[t]{2}{*}{ Coefficient } & \multicolumn{3}{|c|}{ Univariate analysis } & \multicolumn{3}{|c|}{ Multivariate analysis } \\
\hline & Hazard Ratio & $P$ value & $95 \% \mathrm{Cl}$ & Hazard Ratio & $P$ value & $95 \% \mathrm{Cl}$ \\
\hline \multicolumn{7}{|l|}{ Ficat stage } \\
\hline Stage I & 1 (reference) & $<.001$ & 1 (reference) & 1 (reference) & .641 & 1 (reference) \\
\hline Stage \| A & .781 & .749 & $.171-3.565$ & 1.741 & .491 & $.359-8.432$ \\
\hline Stage \| B & 4.749 & .035 & $1.115-20.221$ & 1.162 & .849 & $.249-5.413$ \\
\hline Preoperative Harris score & 1.051 & .190 & $.976-1.132$ & - & - & - \\
\hline \multicolumn{7}{|l|}{ Necrotic location } \\
\hline$A$ & 1 (reference) & $<.001$ & 1 (reference) & 1 (reference) & .582 & 1 (reference) \\
\hline$B$ & .418 & .538 & $.026-6.698$ & .306 & .411 & $.018-5.163$ \\
\hline $\mathrm{C} 1$ & 5.242 & .111 & $.685-40.097$ & 1.231 & .857 & $.127-11.896$ \\
\hline $\mathrm{C} 2$ & 18.644 & .004 & 2.494-139.395 & 1.458 & .752 & $.140-15.145$ \\
\hline \multicolumn{7}{|l|}{ Extent of necrotic lesion } \\
\hline$<15 \%$ & 1 (reference) & $<.001$ & 1 (reference) & 1 (reference) & .001 & 1 (reference) \\
\hline $15-30 \%$ & 3.708 & .109 & $.747-18.408$ & 3.170 & .196 & $.551-18.255$ \\
\hline$>30 \%$ & 32.521 & $<.001$ & $7.695-137.444$ & 22.293 & .001 & $2.506-141.752$ \\
\hline Bone marrow edema & 3.814 & $<.001$ & $1.935-7.518$ & 2.188 & .046 & $1.015-4.719$ \\
\hline \multicolumn{7}{|c|}{ Postoperative work intensity } \\
\hline Grade 0-1 & 1 (reference) & $<.001$ & 1 (reference) & 1 (reference) & .001 & 1 (reference) \\
\hline Grade 2 & 6.004 & $<.001$ & $2.768-13.022$ & 3.579 & .002 & $1.583-8.092$ \\
\hline Grade 3-4 & 6.771 & $<.001$ & $2.833-16.186$ & 5.036 & .001 & $1.863-13.615$ \\
\hline
\end{tabular}

Variables included in the multivariate model if univariate $P$ value $<.05$

\section{Discussion}

In this retrospective study, there was no significant difference in the rate of THA conversion between the multiple drilling group and the natural course group. A larger extent of necrotic lesion, the presence of BME on
MR imaging, and a higher postoperative work intensity were identified as independent risk factors for conversion to THA in patients following multiple drilling procedures for the treatment of early-stage osteonecrosis. Autogenous bone grafting had a protective effect on this
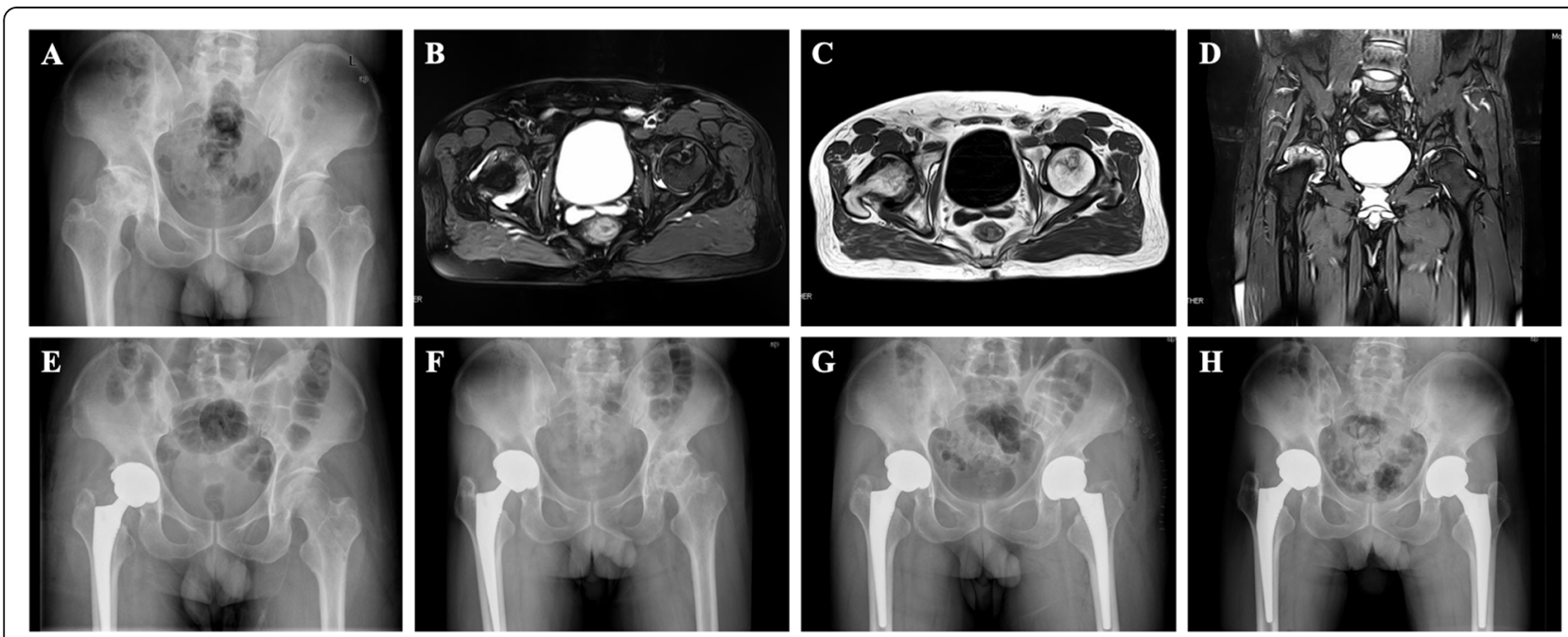

Fig. 4 A Survival analysis of conversion to THA between patients who underwent multiple drilling combined with and without autogenous bone grafting ( $P=.373$, Kaplan-Meier method with log-rank test). Depending on the different extent of necrotic lesion in ONFH patients who underwent multiple drilling, B the survival analysis showed a significant difference in patients with necrotic lesion $<15 \%(P=.007)$ and no significant difference in patients with necrotic lesion of $15-30 \%$ (C) or $>30 \%(\mathbf{D})(P=.453$ and .657 , respectively) 
risk only in patients with extent of necrotic lesion less than $15 \%$.

Most orthopedic surgeons agree that treatment measures should be taken to slow progression and to prevent THA in early-stage ONFH [4]. Multiple drilling is one of the most widespread joint-preserving procedures proposed in recent decades [3]. In theory, this technique is a minimally invasive intervention that provides mechanical support and does not change the anatomic structure of the femoral head which may avoid facture or collapse of the femoral head. However, depending on different types of augmentations, the sample size, and the period of follow-up, variable rates of failure have been reported $[3,5,6,8,20,21]$, and the efficacy of multiple drilling remains controversial. Although several authors have reported improvements in clinical symptoms [3, 6, 8], failure of multiple drilling procedures is a main concern in patients and surgeons. In the current study, there was no difference in the rate of THA conversion in patients following multiple drilling procedures and with a natural course. Similar to our study, a network meta-analysis including only randomized controlled trials demonstrated no differences in the rates of THA conversion and radiologic progression across all core decompression modalities and nonoperative treatment [22]. Another metaanalysis also indicated that multiple drilling did not have significantly better effect on the prevention of THA progression than other therapeutic interventions [23]. The rate of survival following multiple drilling (78.3\%) in our cohort appears to be higher than that reported by the majority of previous studies [6, 24]. The possible reason may be that the present study included only ONFH hips with modified Ficat and Arlet stage I and II. The survival rate of patients with early-stage ONFH was significantly higher than that of patients with postcollapse ONFH [6, 25].

There is constant discussion about the effectiveness of multiple drilling combined with autogenous bone grafting [3]. Autogenous bone grafting is sometimes performed as an ancillary procedure for multiple drilling that may provide structural support for new bone formation with mild inflammatory reactions. Previous studies reported that the success rate of autogenous bone grafting ranged from 55 to $87 \%$ at a follow-up period of 2 to 9 years postoperatively [26-31]. Nelson et al. [32] reported that 52 hips treated by bone grafting had a high rate of radiological progression and concluded that the technique was not effective in halting progression. Survival rates in our cohorts were significantly higher only in patients with small extent of necrotic lesion less than $15 \%$, while autogenous bone grafting did not have a protective effect on the risk of conversion to THA in all early-stage ONFH patients. This is a new finding compared to prior published studies on this matter [25-30].
It may be that autogenous bone provides only shortterm structural support after grafting. For patients with intermediate to larger necrotic lesion, necrotic lesion healing and subchondral bone remodeling may be difficult. Another possible reason may be that the cancellous bone graft in our cohort was harvested from the contralateral femoral neck. Previous studies demonstrated that decreased activity of bone marrow cells in the intertrochanteric region and iliac crest may provide insufficient osteoblasts to meet the need for bone remodeling in the early stage of osteonecrosis [33]. Although this technique has numerous theoretical advantages for the treatment of early-stage lesions, high-quality randomized trials are needed to confirm its efficacy.

A larger extent of necrotic lesion was found to be associated with a higher rate of conversion to THA in the present study. This finding was in line with the results of previous studies $[6,34]$. In a review by Jay R. et al. [34], lower failure rates were found in patients with necrotic lesions involving less than $15 \%$ of the femoral head or with a necrotic angle of less than $200^{\circ}$. Won Seok et al. reported similar results: the survival rates of small necrotic lesions (100\%) and medium-sized lesions (84.1\%) were significantly higher than those of large necrotic lesions (53.8\%) [6]. Stefan et al. reported that no treatment failure was observed in patients with remaining necrosis of less than $1000 \mathrm{~mm}^{3}$ at a mean follow-up of 33 months [35]. One reason for this association may be intuitive as patients with larger necrotic lesion in subchondral lesions may have less mechanical support of the femoral head and a higher risk of hip collapse. Another explanation could be that the amount of remaining necrotic tissue in the larger necrotic lesion was still substantial after small diameters of drilling. Postoperative magnetic resonance imaging showed that removal of the necrotic tissue was rarely complete [36].

Another factor associated with higher rates of conversion to THA was a higher postoperative work intensity. As the disease often affects young and active ONFH patients, the majority of patients wish to return to normal work and have a demand for a high level of physical function. This risk factor for conversion to THA after multiple drilling has not been mentioned in previous studies. In our cohort, $123(77.3 \%)$ of 159 patients had a low level of work intensity after multiple drilling. However, the proportion of patients with medium and high work intensity was significantly higher in the failure group. A high level of work intensity, especially when carrying a heavy load, may increase the load on the hip, which results in accelerated hip collapse.

Interestingly, the presence of $\mathrm{BME}$ on $\mathrm{MR}$ imaging was identified as a risk factor for conversion to THA after multiple drilling in the current study. Previously it has been shown that BME of ONFH is highly correlated 
with the onset of hip pain and an increased risk of subchondral fracture [37, 38]. However, to date, there is no study evaluating the association of BME and conversion to THA after multiple drilling in early-stage ONFH. The underlying mechanisms of this identified link remains elusive, but a possible reason may be that BME represents a secondary sign of subchondral fracture of femoral head. Several prior studies have demonstrated that the presence of subchondral fracture in osteonecrosis is associated with the subsequent collapse of the femoral head which may result in conversion to THA $[39,40]$. Another possible interpretation is that elevated intramedullary pressure caused by BME in the necrotic area may be considered a marker for progression to advanced osteonecrosis. Ito et al. [41] have demonstrated that the radiographic progression of ONFH patients with BME was significantly advanced than those without BME and concluded that the presence of BME might be a sign for deterioration of disease.

We studied the potential association between various radiographic parameters of FAI and failure of multiple drilling. Although the pathologies of the two diseases are totally different, previous studies have reported that the prevalence of CAM-type deformities is greatly increased in patients with ONFH and that CAM-type FAIs may act as a mechanical factor in developing ONFH [42, 43]. In contrast, the prevalence of FAI (10.7\%) in our cohort was significantly lower than that in previous studies, and the association between FAI and failure of multiple drilling was not found. The possible reason may be that the present study included only early-stage osteonecrosis with integrity of the femoral head. For postcollapse ONFH, structural abnormalities of the head-neck junction may lead to impaired blood supply and reduced head-neck offset which accelerate the progression of disease.

We note that there are several limitations in the current study. First, we defined the failure of multiple drilling as conversion to THA. Poor functional outcome and radiographic progression of disease were not included as indicators of failure in our study. This design was deliberate. Absolute failure of multiple drilling, namely, conversion to THA, is an undisputed indicator of failure. With different standards of functional and radiographic outcomes, it is difficult to define the issue of functional and radiographic failure. Second, retrospective data decreased the level of evidence and inevitably resulted in some bias and inaccuracies. Third, there are 4 different surgeons performed multiple drilling procedures in our unit, which inevitably led to variables. However, each of the 4 surgeons had a high volume of ONFH every year, performed similar surgical techniques, and followed the same protocols in treating patients with ONFH.

\section{Conclusion}

Our findings demonstrated that multiple drilling is not effective in delaying or preventing THA in early-stage ONFH patients compared with a natural course of progression. A larger extent of necrotic lesion, the presence of BME on MR imaging, and higher postoperative work intensity were identified as risk factors for treatment failure and conversion to THA in patients following multiple drilling. We emphasized the importance of evaluating necrotic lesion on MR imaging rather than stage alone, and hip-preservation surgeons should be aware of these risk factors for careful patient selection.

\section{Abbreviations \\ ONFH: Osteonecrosis of the femoral head; THA: Total hip arthroplasty; MR imaging: Magnetic resonance imaging; BMI: Body mass index; HHS: Harris hip score; FAl: Femoroacetabular impingement; FNF: Femoral neck fracture; FIF: Femoral intertrochanteric fracture}

\section{Acknowledgements}

We would like to thank the relevant staff for guidance and assistance for their support and collaboration in our hospital.

\section{Authors' contributions}

Zunhan Liu, Xuetao Yang, and Zongke Zhou participated in the design and coordination of the study, collected the data, analyzed the data, and wrote the manuscript. Yuhan Li, Wei-Nan Zeng, and Enze Zhao assisted in collecting the data and writing up. All authors have read and approved the final manuscript. Zunhan Liu, Xuetao Yang contributed equally to this study.

\section{Funding}

This research was supported by Key Research \& Development program of Science \& Technology Department of Sichuan Province (No. 2018SZ0255).

\section{Availability of data and materials}

The datasets used or analyzed in the current study are available from the corresponding author on reasonable request.

\section{Declarations}

\section{Ethics approval and consent to participate}

This study was approved by the Ethics Committee and Institutional Review Board of West China Hospital, Sichuan University (2012-268). Informed consent was obtained from each patient or (dead) patient's next of kin or legally authorization representative of the patient. All methods were performed according to relevant guidelines and regulations.

\section{Consent for publication}

All patients provided consent to participate in current study, per our institution's standard for research consent forms, this consent specified that the research information obtained may be used for publication.

\section{Competing interests}

The corresponding author Dr. Zongke Zhou is a member of the editorial board of BMC Musculoskeletal Disorders, the rest of authors declare they have no competing interests.

Received: 3 February 2021 Accepted: 31 May 2021

Published online: 12 June 2021

References

1. Hart A, Janz V, Trousdale RT, et al. Long-term survivorship of Total hip Arthroplasty with highly cross-linked polyethylene for osteonecrosis. J Bone Joint Surg Am. 2019;101(17):1563-8.

2. Bergh $C$, Fenstad $A M$, Furnes $O$, et al. Increased risk of revision in patients with non-traumatic femoral head necrosis. Acta Orthop. 2014;85(1):11-7.

3. Moon J-K, Yoon JY, Kim C-H, et al. Multiple drilling and multiple matchsticklike bone allografts for large osteonecrotic lesions in the femoral head: an 
average 3-year follow-up study. Arch Orthop Trauma Surg. 2020;140(11): 1655-63.

4. Mont MA, Salem HS, Piuzzi NS, et al. Nontraumatic osteonecrosis of the femoral head: where do we stand today?: a 5-year update. J Bone Joint Surg Am. 2020;102(12):1084-99.

5. Yin H, Yuan Z, Wang D. Multiple drilling combined with simvastatin versus multiple drilling alone for the treatment of avascular osteonecrosis of the femoral head: 3-year follow-up study. BMC Musculoskelet Disord. 2016;17(1):1-8.

6. Song WS, Yoo JJ, Kim YM, Kim HJ. Results of multiple drilling compared with those of conventional methods of core decompression. Clin Orthop Relat Res. 2007:454:139-46.

7. Kang P, Pei F, Shen B, et al. Are the results of multiple drilling and alendronate for osteonecrosis of the femoral head better than those of multiple drilling? A pilot study. Joint Bone Spine. 2012;79(1):67-72.

8. Al OA. Multiple drilling compared with standard core decompression for avascular necrosis of the femoral head in sickle cell disease patients. Arch Orthop Trauma Surg. 2013;133(5):609-13.

9. Bae JY, Kwak DS, Park KS, et al. Finite element analysis of the multiple drilling technique for early osteonecrosis of the femoral head. Ann Biomed Eng. 2013;41(12):2528-37.

10. Mohanty SP, Singh KA, Kundangar R, et al. Management of non-traumatic avascular necrosis of the femoral head-a comparative analysis of the outcome of multiple small diameter drilling and core decompression with fibular grafting. Musculoskelet Surg. 2017;101(1):59-66.

11. Hong YC, Zhong HM, Lin T, et al. Comparison of core decompression and conservative treatment for avascular necrosis of femoral head at early stage: a meta-analysis. Int J Clin Exp Med. 2015;8(4):5207-16.

12. Roth A, Beckmann J, Bohndorf K, et al. S3-guideline non-traumatic adult femoral head necrosis. Arch Orthop Trauma Surg. 2016;136(2):165-74.

13. Smith SW, Fehring TK, Griffin WL, et al. Core decompression of the osteonecrotic femoral head. J Bone Joint Surg Am. 1995;77(5):674-80.

14. Harris WH. Traumatic arthritis of the hip after dislocation and acetabular fractures: treatment by mold arthroplasty. An end-result study using a new method of result evaluation. J Bone Joint Surg Am. 1969;51(4):737-55.

15. Mont MA, Ragland PS, Etienne G. Core decompression of the femoral head for osteonecrosis using percutaneous multiple small-diameter drilling. Clin Orthop Relat Res. 2004;429:131-8

16. Kraus TM, Abele C, Freude T, et al. Duration of incapacity of work after tibial plateau fracture is affected by work intensity. BMC Musculoskelet Disord. 2018;19(1):281.

17. Sugano N, Atsumi T, Ohzono K, et al. The 2001 revised criteria for diagnosis, classification, and staging of idiopathic osteonecrosis of the femoral head. J Orthop Sci. 2002;7(5):601-5.

18. Steinberg ME, Hayken GD, Steinberg DR. A quantitative system for staging avascular necrosis. J Bone Joint Surg Br. 1995;77(1):34-41.

19. Steinberg DR, Steinberg ME, Garino JP, et al. Determining lesion size in osteonecrosis of the femoral head. J Bone Joint Surg Am. 2006;88(Suppl 3): 27-34.

20. Bozic KJ, Zurakowski D, Thornhill TS. Survivorship analysis of hips treated with core decompression for nontraumatic osteonecrosis of the femoral head. J Bone Joint Surg Am. 1999:81(2):200-9.

21. Mont MA, Carbone JJ, Fairbank AC. Core decompression versus nonoperative management for osteonecrosis of the hip. Clin Orthop Relat Res. 1996;324:169-78.

22. Yoon BH, Lee YK, Kim KC, et al. No differences in the efficacy among various core decompression modalities and non-operative treatment: a network meta-analysis. Int Orthop. 2018;42(12):2737-43.

23. Wang J, Wang J, Zhang K, et al. Bayesian network meta-analysis of the effectiveness of various interventions for nontraumatic osteonecrosis of the femoral head. Biomed Res Int. 2018;2018:2790163.

24. Andronic $\mathrm{O}$, Weiss $\mathrm{O}$, Shoman $\mathrm{H}$, et al. What are the outcomes of core decompression without augmentation in patients with nontraumatic osteonecrosis of the femoral head? Int Orthop. 2020;45(3):605-13.

25. Mont MA, Cherian JJ, Sierra RJ, et al. Nontraumatic osteonecrosis of the femoral head: where do we stand today? J Bone Joint Surg Am. 2015. 97(19):1604-27.

26. Hsu JE, Wihbey T, Shah RP, et al. Prophylactic decompression and bone grafting for small asymptomatic osteonecrotic lesions of the femoral head. Hip Int. 2011;21(6):672-7.
27. Zhang HJ, Liu YW, Du ZQ, et al. Therapeutic effect of minimally invasive decompression combined with impaction bone grafting on osteonecrosis of the femoral head. Eur J Orthop Surg Traumatol. 2013;23(8):913-9.

28. Helbig L, Simank HG, Kroeber M, et al. Core decompression combined with implantation of a demineralised bone matrix for non-traumatic osteonecrosis of the femoral head. Arch Orthop Trauma Surg. 2012;132(8): 1095-103.

29. Wei BF, Ge XH. Treatment of osteonecrosis of the femoral head with core decompression and bone grafting. Hip Int. 2018;21(2):206-10.

30. Yang $S, W u X, X u$ W, et al. Structural augmentation with biomaterial-loaded allograft threaded cage for the treatment of femoral head osteonecrosis. J Arthroplast. 2010;25(8):1223-30.

31. Wang BL, Sun W, Shi ZC, et al. Treatment of nontraumatic osteonecrosis of the femoral head using bone impaction grafting through a femoral neck window. Int Orthop. 2010;34(5):635-9.

32. Nelson LM, Clark CR. Efficacy of phemister bone grafting in nontraumatic aseptic necrosis of the femoral head. J Arthroplast. 1993;8(3):253-8.

33. Hernigou P, Beaujean F, Lambotte JC. Decrease in the mesenchymal stemcell pool in the proximal femur in corticosteroid-induced osteonecrosis. J Bone Joint Surg Br. 1999;81(2):349-55.

34. Lieberman JR, Engstrom SM, Meneghini RM, et al. Which factors influence preservation of the Osteonecrotic femoral head? Clin Orthop Relat Res. 2011;470(2):525-34.

35. Landgraeber S, Tran TN, Claßen T, et al. Geometric analysis of an expandable reamer for treatment of avascular necrosis of the femoral head. Arch Orthop Trauma Surg. 2015:135(10):1357-62.

36. Landgraeber S, Theysohn JM, Classen T, et al. Advanced core decompression, a new treatment option of avascular necrosis of the femoral head. J Tissue Eng Regen Med. 2013;7(11):893-900.

37. Meier R, Kraus TM, Schaeffeler $C$, et al. Bone marrow oedema on MR imaging indicates ARCO stage 3 disease in patients with AVN of the femoral head. Eur Radiol. 2014;24(9):2271-8.

38. Hatanaka H, Motomura $\mathrm{G}$, Ikemura $\mathrm{S}$, et al. Differences in magnetic resonance findings between symptomatic and asymptomatic pre-collapse osteonecrosis of the femoral head. Eur J Radiol. 2019:112:1-6.

39. Iida S, Harada Y, Shimizu K, et al. Correlation between bone marrow edema and collapse of the femoral head in steroid-induced osteonecrosis. AJR Am J Roentgenol. 2000;174(3):735-43.

40. Kim YM, Oh HC, Kim HJ. The pattern of bone marrow oedema on MRI in osteonecrosis of the femoral head. J Bone Joint Surg Br. 2000;82(6):837-41.

41. Ito H, Matsuno T, Minami A. Relationship between bone marrow edema and development of symptoms in patients with osteonecrosis of the femoral head. AJR Am J Roentgenol. 2006;186(6):1761-70.

42. Serong $\mathrm{S}$, Haversath $\mathrm{M}$, Jager $\mathrm{M}$, et al. Prevalence of CAM deformity and its influence on therapy success in patients with osteonecrosis of the femoral head. J Tissue Eng Regen Med. 2019;13(4):546-54.

43. Fraitzl CR, Kappe T, Brugger A, et al. Reduced head-neck offset in nontraumatic osteonecrosis of the femoral head. Arch Orthop Trauma Surg. 2013;133(8):1055-60

\section{Publisher's Note}

Springer Nature remains neutral with regard to jurisdictional claims in published maps and institutional affiliations.

Ready to submit your research? Choose BMC and benefit from:

- fast, convenient online submission

- thorough peer review by experienced researchers in your field

- rapid publication on acceptance

- support for research data, including large and complex data types

- gold Open Access which fosters wider collaboration and increased citations

- maximum visibility for your research: over $100 \mathrm{M}$ website views per year

At $\mathrm{BMC}$, research is always in progress.

Learn more biomedcentral.com/submission 